\title{
AÇÃo de Herbicidas na Atividade de BaCtérias Solubilizadoras De Fosfato da Rizosfera de CANA-DE-AçÚCAR ${ }^{1}$
}

\author{
Action of Herbicides on the Activity of Phosphate-solubilizing Bacteria Isolated from Sugarcane \\ Rhizosphere
}

\author{
TIRONI, S.P. ${ }^{2}$, REIS, M.R. ${ }^{2}$, GALON, L. ${ }^{2}$, FREITAS, M.A.M. ${ }^{3}$, COSTA, M.D. ${ }^{4}$, SILVA, A.A. ${ }^{5}$, \\ BARBOSA, M.H.P. ${ }^{5}$ e PETERNELLI, L.A. ${ }^{6}$
}

\begin{abstract}
RESUMO - Objetivou-se com este trabalho avaliar a ação de herbicidas na atividade e no crescimento de isolados bacterianos solubilizadores de fosfato, provenientes da rizosfera de plantas de cana-de-açúcar. Dois isolados bacterianos, Sac 4 e Sac 13, classificados como de alta e de baixa capacidade de solubilização de fosfato inorgânico, respectivamente, foram usados no experimento. O crescimento e a atividade dos isolados solubilizadores foram avaliados na presença dos herbicidas trifloxysulfuron-sodium, ametryn e trifloxysulfuronsodium + ametryn, nas doses de $0,1 / 2,3 / 4,1$ e 2 vezes a dose de referência $(0,45,60$ e $0,74+$ $30 \mathrm{mg} \mathrm{L}^{-1}$, respectivamente). O isolado Sac 4 teve seu crescimento reduzido na presença dos herbicidas ametryn e trifloxysulfuron-sodium + ametryn, sendo a maior redução na presença da mistura (92,43\%). Não se observaram efeitos dos herbicidas no crescimento do isolado bacteriano Sac 13. A atividade solubilizadora de fosfato inorgânico de ambos os isolados não foi alterada na presença dos herbicidas, indicando que esses compostos apresentam seletividade a algumas populações de microrganismos do solo.
\end{abstract}

Palavras-chave: trifloxysulfuron-sodium, ametryn, microrganismos do solo.

\begin{abstract}
The objective of this work was to evaluate the effects of herbicides on the phosphate-solubilizing activity and growth of bacteria isolated from sugarcane rhizosphere. Two bacterial isolates, Sac 4 and Sac 13, classified as being of high and low capability of solubilizing inorganic phosphate, respectively, were used in the experiments. The growth and phosphatesolubilizing activities were evaluated in the presence of trifloxysulfuron-sodium, ametryn, and trifloxysulfuron-sodium + ametryn, at $0,1 / 2,3 / 4,1$, and 2 times the reference dose $10.45,60,0.74+$ $30 \mathrm{mg} \mathrm{L}^{-1}$, respectively). For Sac 4, the herbicides ametryn and trifloxysulfuron-sodium + ametryn reduced growth, with the largest reduction being observed for trifloxysulfuron-sodium + ametryn, while for Sac 13, no effect of the herbicides was observed. The phosphate-solubilizing activity of both bacterial isolates was not affected by the herbicides tested; this indicates that the impact of these compounds on the soil microorganisms is selective to certain populations.
\end{abstract}

Keywords: trifloxysulfuron-sodium, ametryn, soil microorganisms.

\section{INTRODUÇÃO}

A disponibilidade de nutrientes é um dos fatores determinantes para o desenvolvimento vegetal, sendo o fósforo $(\mathrm{P})$ considerado o mais crítico (Siqueira et al., 2004). As formas insolúveis de $\mathrm{P}$ presentes no solo podem ser divididas em orgânicas, que estão ligadas aos complexos de matéria orgânica, e em inorgânicas, que podem se encontrar precipitadas

Recebido para publicação em 12.4.2009 e na forma revisada em 13.11.2009.

2 Engo-Agrọ ${ }^{\text {. }}$ aluno do Programa de Pós-Graduação em Fitotecnia, Universidade Federal de Viçosa - DFT/UFV, 36570-000 ViçosaMG, <siumar.tironi@ufv.br>; ${ }^{3}$ Estudante de agronomia - DFT/UFV; ${ }^{4}$ Engo-Agr ${ }^{\circ}$. , D.Sc., Prof. do Dep. de Microbiologia - DMB/ UFV; ${ }^{5}$ Engo-Agr ${ }^{0}$., D.Sc., Prof. do Dep. de Fitotecnia - DFT/UFV, Bolsista do CNPq; ${ }^{6}$ Engo-Agro ${ }^{\circ}$, Ph.D., Professor do Dep. de Informática - DPI/UFV, Bolsista do CNPq. 
com íons $\mathrm{Ca}^{2+}, \mathrm{Fe}^{3+} \mathrm{e}^{3+}$ ou adsorvidas à superfície de partículas minerais do solo (Moreira \& Siqueira, 2006).

A liberação do $P$ insolúvel na forma orgânica geralmente envolve a ação de enzimas denominadas, de maneira geral, como fosfatases. Quando na forma inorgânica, a liberação do fosfato feita por fatores estritamente físicoquímicos e alterações nesses fatores promovem o deslocamento do equilíbrio para um ou outro compartimento (Novais et al., 2007). O deslocamento do equilíbrio no sentido dos produtos solúveis é obtido pelas alterações de fatores como o potencial hidrogenionico $(\mathrm{pH})$ do solo, em que menores valores de $\mathrm{pH}$ favorecem a solubilização do fosfato inorgânico e a quelação de cátions por ácidos orgânicos. Desse modo, a maior solubilização de fosfato inorgânico ocorre na rizosfera das plantas, devido à acidificação, em decorrência da liberação de prótons pela planta e de ácidos orgânicos pelos microrganismos, sendo estes denominados de microrganismos solubilizadores de fosfato inorgânico (MSFI) (Rodríguez \& Fraga, 1999).

Vários trabalhos têm demonstrado a importância dos MSFI do solo rizosférico das culturas no suprimento de $\mathrm{P}$ e também na promoção de crescimento de plantas (Freitas et al., 1997; Gyaneshwar et al., 2002; Sundara et al., 2002). A efetividade dos MSFI depende da interação destes com a planta hospedeira e de sua microbiota associada. Vários fatores influenciam a capacidade de solubilização desses microrganismos, a exemplo da fonte de carbono e nitrogênio disponíveis (Nautiyal et al., 2000), da espécie cultivada (Grayston et al., 1996), da fonte de fosfato a ser solubilizado (Nahas, 1996; Barroso \& Nahas, 2005), entre outros, como a presença de agrotóxicos - inseticidas, fungicidas e herbicidas (Das \& Mukherjee, 1998; Debnath, 2002; Das, 2003; Reis et al., 2008a).

A utilização de herbicidas em cultivos comerciais tem grande importância no manejo das plantas daninhas, as quais competem com as culturas por água, luz e nutrientes, ocasionando perdas de produtividade. Além disso, quando não controladas adequadamente em canaviais, as plantas daninhas podem reduzir a qualidade do produto colhido e a longevidade destes (Negrisoli et al., 2004). Para o manejo das plantas daninhas em lavouras de cana-de-açúcar no Brasil, o uso da mistura comercial dos herbicidas ametryn e trifloxysulfuron-sodium, desde 2001, tem-se expandido em razão do amplo espectro de ação e do controle eficiente da tiririca (Cyperus rotundus), considerada uma espécie daninha de difícil controle (Reis et al., 2008c). No entanto, o ametryn, o trifloxysulfuron-sodium e a mistura de ambos podem interferir na atividade microbiana da rizosfera de plantas de cana-de-açúcar quando cultivadas em casa de vegetação (Reis et al., 2008a). O trifloxysulfuron-sodium apresenta ação sistêmica, sendo translocado por todas as partes da planta (Silva et al., 2007). Ao contrário, o ametryn apresenta somente translocação acrópeta nas plantas, sendo, portanto, pouco provável sua presença nos exsudatos radiculares. No entanto, acredita-se que este herbicida possa atingir a rizosfera pela percolação no solo. De acordo com Law (2001), cerca de $70 \%$ do herbicida atinge o solo no momento da sua aplicação. O ametryn e o trifloxysulfuronsodium apresentam alta mobilidade no perfil do solo, principalmente em solos arenosos e com baixo teor de matéria orgânica (Vivian et al., 2007); por isso, podem atingir com facilidade a rizosfera das plantas cultivadas.

$\mathrm{Na}$ literatura foram encontrados poucos relatos de trabalhos realizados para avaliar a toxicidade in vitro de herbicidas sobre bactérias solubilizadoras de fosfato inorgânico. De acordo com Alves et al. (1998), os estudos in vitro têm a vantagem de expor ao máximo o microrganismo à ação do agrotóxico, fato que não ocorre em condições de campo, onde vários fatores servem de obstáculo a essa exposição. Desse modo, a não toxicidade de um produto ao microrganismo em laboratório confirma a sua seletividade no campo. Todavia, a alta toxicidade de um composto in vitro nem sempre indica a sua elevada toxicidade em campo, mas sim a possibilidade da ocorrência de danos dessa natureza. Nóbrega et al. (2004) acrescentam que os testes in vitro são rápidos e de custo relativamente baixo.

Objetivou-se com este trabalho avaliar o efeito dos herbicidas ametryn, trifloxysulfuronsodium e a mistura comercial deles no crescimento e na atividade de isolados bacterianos solubilizadores de fosfato inorgânico obtidos de solo rizosférico de plantas de cana-de-açúcar. 


\section{MATERIAL E MÉTODOS}

Amostras de solo rizosférico de cinco lavouras de cana-de-açúcar foram coletadas e caracterizadas quimicamente (Tabela 1). Todas as lavouras localizam-se no municipio de Viçosa-MG e não apresentavam histórico de aplicação de herbicidas.

Para obtenção dos isolados bacterianos solubilizadores de fosfato, foram preparadas diluições seriadas até a $10^{-5}$, a partir da suspensão de $10 \mathrm{~g}$ de solo rizosférico de plantas de cana-de-açúcar em $90 \mathrm{~mL}$ de solução salina $(\mathrm{NaCl} 0,85 \%)$, com três repetições. Alíquotas de $0,1 \mathrm{~mL}$ das diluições $10^{-3}, 10^{-4} \mathrm{e}$ $10^{-5}$ foram inoculadas na superfície do meio glicose-extrato de levedura (GEL), suplementado com fosfato de cálcio. Após sete dias de incubação a $30^{\circ} \mathrm{C}$, as bactérias solubilizadoras de fosfato inorgânico foram selecionadas pela presença de halos de solubilização em torno da colônia.

Cada isolado foi inoculado e reinoculado na superficie do meio GEL, e ambas as inoculações incubadas por sete dias a $30{ }^{\circ} \mathrm{C}$. Posteriormente, foi determinado o indice de solubilização (IS) de fosfato de cálcio, obtido pela razão entre o diâmetro do halo e o diâmetro da colônia, conforme descrito por Kumar \& Narula (1999), sendo a capacidade de solubilização de fosfato classificada em baixa (IS < 2), média $(2<$ IS < 3 ) e alta (IS > 3), de acordo com Silva Filho \& Vidor (2000).

Vinte isolados bacterianos solubilizadores de fosfato inorgânico foram obtidos (Tabela 2). Esses isolados diferiram quanto à capacidade de solubilizar fosfato de cálcio in vitro, apresentando índices de solubilização (IS) entre 1,26 e 3,66 (Tabela 2).

Para avaliação de crescimento, foram selecionados dois isolados bacterianos, o Sac 4 e o Sac 13, classificados como de alta e baixa capacidade de solubilização, respectivamente (extremos das amostras coletadas). O experimento foi realizado em delineamento inteiramente casualizado, com seis repetições. Os tratamentos foram dispostos em esquema fatorial ( $3 \times 5 \times 48)$ para cada isoldado bacteriano, sendo o fator A composto pelos herbicidas Envoke $^{\circledR}$ (trifloxysulfuron-sodium - 0,45 $\mathrm{mg} \mathrm{L}^{-1}$ ), Metrimex $500 \mathrm{SC}^{\circledR}$ (ametryn - $60 \mathrm{mg} \mathrm{L}^{-1}$ ) e
Krismat ${ }^{\circledR}$ (ametryn + trifloxysulfuron-sodium $\left.30+0,74 \mathrm{mg} \mathrm{L}^{-1}\right)$; o fator $\mathrm{B}$, pelas doses de $0,1 / 2$, $3 / 4,1$ e 2 vezes a de referência (correspondente às doses comerciais recomendadas); e o fator $\mathrm{C}$, pelos períodos de avaliação, com intervalo de uma hora durante 48 horas. O ensaio foi conduzido em placas de Elisa contendo $150 \mu \mathrm{L}$ de meio caldo nutriente, suplementado com as doses de herbicidas, onde foram inoculados isolados Sac 4 e Sac 13, previamente cultivados por $24 \mathrm{~h}$ a $30^{\circ} \mathrm{C}$ em meio caldo nutriente. As placas foram incubadas a $30^{\circ} \mathrm{C}$ por $48 \mathrm{~h}$, sendo as taxas de crescimento dos isolados avaliadas em intervalos de uma hora, por meio de leituras em espectrofotômetro com filtro de $560 \mathrm{~nm}$. O crescimento relativo dos isolados foi comparado nos tratamentos com os herbicidas na dose de referência, considerando o tratamento com a dose zero como o crescimento-padrão (100\%). As demais avaliações foram realizadas comparando o crescimento dos isolados bacterianos em cada tratamento com herbicidas e doses ao longo do tempo.

Também foi avaliado o potencial de solubilização de fosfato dos isolados bacterianos, perfazendo um tratamento fatorial $(2 \times 4)$, em que o primeiro fator foi composto pelos isolados bacterianos Sac 4 e Sac 13 e o segundo, pelos herbicidas ametryn, ametryn + trifloxysulfuron-sodium e trifloxysulfuronsodium, nas doses de referência, além de um tratamento sem aplicação de herbicidas. Ambos os isolados foram inoculados em erlenmeyers contendo $50 \mathrm{~mL}$ de meio NBRIP líquido (Nautiyal, 1999), com adição de fosfato de cálcio $\left(\mathrm{Ca}_{5} \mathrm{P}_{3} \mathrm{HO}_{13}\right)$ em quantidade equivalente a $5 \mathrm{~g} \mathrm{~L}^{-1}$ de $\mathrm{P}$, suplementado com os herbicidas. Os erlenmeyers contendo os tratamentos foram submetidos à agitação $(200 \mathrm{rpm})$ por três dias, a $30{ }^{\circ} \mathrm{C}$ (três repetições por tratamento).

A inoculação foi realizada por meio de uma alça, transferindo-se células previamente cultivadas por $24 \mathrm{~h}$ a $30^{\circ} \mathrm{C}$ em tubos de Ágar Nutriente inclinado. Após a incubação, determinou-se o potencial hidrogeniônico $(\mathrm{pH})$ do meio e, posteriormente, realizou-se a centrifugação por 20 minutos a $8.000 \mathrm{rpm}$; a determinação do fósforo solúvel do sobrenadante foi feita pelo método colorimétrico descrito por Braga \& De Fellipo (1974). 
Os dados foram submetidos à análise de variância $(\mathrm{F})$; sendo eles significativos, os fatores qualitativos foram comparados por meio de contrastes ortogonais (Tabela 3), utilizando o software estatístico SAS. Os fatores quantitativos foram avaliados por regressão, e a escolha dos modelos foi baseada na significância estatística $\left(\mathrm{F}\right.$ e $\left.\mathrm{R}^{2}\right)$ e na explicação biológica, conforme o modelo utilizado por Massenssini et al. (2008). As regressões foram comparadas pelo teste de identidade de modelos, onde os completos foram comparados com o modelo reduzido (Regazzi \& Silva, 2004). Em todos os testes utilizou-se o nível de $5 \%$ de significância.

\section{RESULTADOS E DISCUSSÃO}

Os resultados demonstraram que o isolado bacteriano Sac 13 apresentou maior crescimento relativo, em relação ao Sac 4, em todos os tratamentos (Tabela 4). Observou-se estímulo ao crescimento com os tratamentos para o Sac 13 (101,46\%), enquanto o Sac 4 foi prejudicado pelos herbicidas.

Comparando os tratamentos com herbicidas com a testemunha, para o isolado Sac 4, não se observaram efeitos dos tratamentos no crescimento bacteriano. Contudo, entre os herbicidas, observou-se maior crescimento quando tratado com o trifloxysulfuron-sodium. Comparando os tratamentos com ametryn e a mistura de trifloxysulfuron-sodium + ametryn, não se observou diferença (Tabela 4). Reis et al. (2008a), ao avaliarem os efeitos de herbicidas sobre atividade microbiana da rizosfera de plantas de cana-de-açúcar, verificaram que o trifloxysulfuron-sodium não foi prejudicial aos microrganismos do solo, ao passo que o ametryn, o 2,4-D e a mistura comercial de trifloxysulfuron-sodium + ametryn influenciaram negativamente a microbiota do solo.

A interferência do ametryn e do trifloxysulfuron-sodium + ametryn nos microrganismos do solo é atribuida, em parte, não aos ingredientes ativos, mas de outros compostos presentes nas formulações. Alguns autores associam os efeitos dos herbicidas sobre os microrganismos aos solventes, surfatantes e agentes molhantes presentes nas formulações (Malkones, 2000; Santos et al., 2004).

$\mathrm{Na}$ avaliação do crescimento relativo do isolado bacteriano Sac 13, não foram observadas diferenças ao se comparar a testemunha sem herbicida com os tratamentos com herbicidas (Tabela 4). Também não foram observadas diferenças quando comparados os tratamentos herbicidas entre si (Tabela 4). Desse modo, evidencia-se a menor influência dos herbicidas no crescimento do Sac 13 . Esses resultados corroboram os encontrados por Massenssini et al. (2008), os quais verificaram que as formulações de glyphosate reduziram, in vitro, o crescimento relativo em 50 e $14 \%$ de bactérias de alta e baixa capacidade de solubilização de fosfato inorgânico, respectivamente.

Houve diferença na atividade de solubilização de fosfato inorgânico ao se contrastarem os dois isolados bacterianos entre si; em todos os tratamentos, os maiores valores foram observados no Sac 4, comprovando assim o maior potencial de solubilização de fosfato inorgânico desse isolado (Tabela 4).

Tabela 1 - Características químicas das amostras $(0-10 \mathrm{~cm})$ de solo coletadas em lavouras canavieiras do município de Viçosa, Minas Gerais. Viçosa-MG, 2008

\begin{tabular}{|c|c|c|c|c|c|c|c|c|c|c|c|}
\hline \multirow{3}{*}{ Local $^{2 /}$} & \multicolumn{11}{|c|}{ Característica química $^{1 /}$} \\
\hline & \multirow{2}{*}{$\frac{\mathrm{pH}}{\left(\mathrm{H}_{2} \mathrm{O}\right)}$} & $P$ & $\mathrm{~K}^{+}$ & $\mathrm{H}+\mathrm{Al}$ & $\mathrm{Al}^{3+}$ & $\mathrm{Ca}^{2+}$ & $\mathrm{Mg}^{2+}$ & $\mathrm{T}$ & $\mathrm{V}$ & $\mathrm{m}$ & \multirow{2}{*}{$\frac{\mathrm{MO}}{\left(\mathrm{dag} \mathrm{kg}^{-1}\right)}$} \\
\hline & & \multicolumn{2}{|c|}{$\left.(\mathrm{mg} \mathrm{dm})^{-3}\right)$} & \multicolumn{5}{|c|}{$\left(\mathrm{cmol}_{\mathrm{c}} \mathrm{dm}^{-3}\right)$} & \multicolumn{2}{|c|}{$(\%)$} & \\
\hline 01 & $\overline{5,9}$ & 3,4 & 52 & 3,47 & 0,0 & 1,7 & 1,0 & 6,30 & 45 & 0,0 & 1,9 \\
\hline 02 & 6,5 & 10,9 & 126 & 1,98 & 0,0 & 4,9 & 1,5 & 8,70 & 77 & 0,0 & 2,6 \\
\hline 03 & 6,4 & 9,6 & 58 & 1,32 & 0,0 & 2,0 & 1,2 & 4,67 & 72 & 0,0 & 1,1 \\
\hline 04 & 5,4 & 10,4 & 138 & 5,78 & 0,1 & 2,4 & 0,8 & 9,33 & 38 & 3,0 & 1,7 \\
\hline 05 & 5,8 & 2,2 & 42 & 4,95 & 0,0 & 2,2 & 1,0 & 8,26 & 40 & 0,0 & 2,4 \\
\hline
\end{tabular}

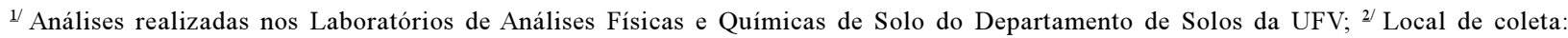
01) Fazenda Bom Sucesso; 02) Fazenda Hipoteca; 03) Fazenda Morro Grande; 04) Fazenda Recanto de Maria; e 05) Viveiro Jurandir. T: capacidade da troca de cátions (pH 7); V: saturação de bases; m: saturação de alumínio; MO: matéria orgânica. 
Tabela 2 - Isolados bacterianos solubilizadores de fosfato inorgânico, índice de solubilização (IS) e procedência (local de coleta). Viçosa-MG, 2008

\begin{tabular}{|c|l|l|l|}
\hline Número & Isolado & IS & \multicolumn{1}{|c|}{ Local de coleta } \\
\hline 01 & Sac 8 & 3,22 & Fazenda Bom Sucesso \\
\hline 02 & Sac 20 & 1,26 & Fazenda Bom Sucesso \\
\hline 03 & Sac 1 & 2,31 & Fazenda Hipoteca \\
\hline 04 & Sac 6 & 2,02 & Fazenda Hipoteca \\
\hline 05 & Sac 7 & 3,28 & Fazenda Hipoteca \\
\hline 06 & Sac 9 & 1,67 & Fazenda Hipoteca \\
\hline 07 & Sac 3 & 2,90 & Fazenda Morro Grande \\
\hline 08 & Sac 5 & 3,17 & Fazenda Morro Grande \\
\hline 09 & Sac 11 & 2,44 & Fazenda Morro Grande \\
\hline 10 & Sac 17 & 2,37 & Fazenda Morro Grande \\
\hline 11 & Sac 13 & 1,44 & Fazenda Recanto de Maria \\
\hline 12 & Sac 2 & 3,23 & Viveiro Jurandir \\
\hline 13 & Sac 4 & 3,66 & Viveiro Jurandir \\
\hline 14 & Sac 10 & 1,32 & Viveiro Jurandir \\
\hline 15 & Sac 12 & 2,57 & Viveiro Jurandir \\
\hline 16 & Sac 14 & 3,00 & Viveiro Jurandir \\
\hline 17 & Sac 15 & 1,33 & Viveiro Jurandir \\
\hline 18 & Sac 16 & 3,42 & Viveiro Jurandir \\
\hline 19 & Sac 18 & 3,23 & Viveiro Jurandir \\
\hline 20 & Sac 19 & 3,00 & Viveiro Jurandir \\
\hline
\end{tabular}

Tabela 3 - Estimativa dos contrastes ortogonais de crescimento relativo (\%) e potencial de solubilização de fosfato inorgânico dos isolados bacterianos, tratados com a dose de referência dos herbicidas

\begin{tabular}{|c|c|c|c|c|c|c|c|c|}
\hline \multirow{2}{*}{\multicolumn{2}{|c|}{ Tratamento }} & \multicolumn{7}{|c|}{ Contraste ortogonal } \\
\hline & & $\mathrm{C}_{1}$ & $\mathrm{C}_{2}$ & $\mathrm{C}_{3}$ & $\mathrm{C}_{4}$ & $\mathrm{C}_{5}$ & $\mathrm{C}_{6}$ & $\mathrm{C}_{7}$ \\
\hline 1. Sac 4 & Testemunha & + & + & & & & & \\
\hline 2. Sac 4 & $\mathrm{HA}^{\underline{1} /}$ & + & - & + & & & & \\
\hline 3. Sac 4 & $\mathrm{HB}^{2 /}$ & + & - & - & + & & & \\
\hline 4. $\mathrm{Sac} 4$ & $\mathrm{HC}^{3 /}$ & + & - & - & - & & & \\
\hline 5. Sac 13 & Testemunha & - & & & & + & & \\
\hline 6. Sac 13 & $\mathrm{HA}^{1 /}$ & - & & & & - & + & \\
\hline 7. Sac 13 & $\mathrm{HB}^{2 /}$ & - & & & & - & - & + \\
\hline 8. Sac 13 & $\mathrm{HC}^{3 /}$ & - & & & & - & - & - \\
\hline
\end{tabular}

1/ HA: trifloxysulfuron-sodium, marca comercial Envoke ${ }^{\otimes}$, ${ }^{2 /} \mathrm{HB}$ : ametryn, marca comercial Metrimex $500 \mathrm{SC}^{\otimes}$; $3 / \mathrm{HC}$ : trifloxysulfuron-sodium + ametryn, marca comercial Krismat ${ }^{\circledR}$.

Para o isolado Sac 4 não foram observadas diferenças entre a testemunha e os tratamentos com herbicidas no potencial de solubilização de fosfato inorgânico (Tabela 4). No entanto, maior valor foi observado no tratamento com trifloxysulfuron-sodium em relação aos demais herbicidas. Não se constatou distinção na variável estudada ao comparar os tratamentos com ametryn e a mistura sobre o isolado Sac 4 (Tabela 4). Esse resultado está de acordo com o encontrado por Reis et al. (2008b), que observaram redução do potencial de solubilização de fosfato inorgânico pela microbiota do solo rizosférico de cana-deaçúcar após a aplicação do ametryn isolado ou em mistura com o trifloxysulfuron-sodium. Madhaiyan et al. (2006) relataram que o atrazine (mesmo grupo químico do ametryn), inibidor do fotossistema II, reduziu pela metade a atividade solubilizadora de fosfato inorgânico da bactéria Gluconoacetobacter diazotrophicus.

Para o Sac 13, não foram observadas diferenças quando comparados os tratamentos com aplicação dos herbicidas com a testemunha, nem entre os tratamentos com herbicidas entre si, para a variável potencial de solubilização de fosfato inorgânico (Tabela 4), demonstrando assim a menor sensibilidade desse isolado aos herbicidas testados.

De acordo com o teste de identidade de modelos, observou-se que a aplicação dos herbicidas nas diferentes doses alterou a taxa de crescimento dos isolados bacterianos de forma diferenciada, o que foi verificado pela não sobreposição das curvas de presença e ausência dos herbicidas (Figura 1 e 2).

Para o isolado bacteriano Sac 4, verificouse que o crescimento na presença dos herbicidas foi afetado em todas as doses testadas (Figura 1B, C), com exceção do trifloxysulfuronsodium (Figura 1A). Apesar de bactérias possuírem a enzima acetolactato sintase (ALS), o trifloxysulfuron-sodium, inibidor dessa enzima, não se mostrou prejudicial. As curvas dos tratamentos com $1 / 2,3 / 4$ e 1 vez a dose de ametryn não diferiram entre si, porém foram diferentes da curva sem aplicação do herbicida e da curva de dose 2 vezes, evidenciando-se que a metade da dose apresenta o mesmo potencial de risco da dose de referência, mas menor que o dobro da dose (Figura 1B). O trifloxysulfuron-sodium + ametryn apresentou efeito negativo no crescimento desse isolado em todas as doses testadas (Figura 1C). Na dose de referência, nenhum dos herbicidas afetou a taxa de crescimento, em relação ao tratamento sem herbicida (Figura 1D). 
Tabela 4 - Crescimento relativo e fósforo liberado pelos isolados bacterianos da rizosfera de cana-de-açúcar cultivados em meio líquido NBRIP, suplementado com os herbicidas trifloxysulfuron-sodium, ametryn e trifloxysulfuron-sodium + ametryn, na dose de referência, por 48 horas a $30^{\circ} \mathrm{C}$ e por três dias a $30{ }^{\circ} \mathrm{C}$, respectivamente. Viçosa-MG, 2008

\begin{tabular}{|c|c|c|c|c|c|c|c|}
\hline \multirow{3}{*}{ Variável avaliada } & \multicolumn{7}{|c|}{ Contraste ortogonal $^{1 /}$} \\
\cline { 2 - 8 } & $\mathrm{C}_{1}$ & $\mathrm{C}_{2}$ & $\mathrm{C}_{3}$ & $\mathrm{C}_{4}$ & $\mathrm{C}_{5}$ & $\mathrm{C}_{6}$ & $\mathrm{C}_{7}$ \\
\cline { 2 - 9 } & $(1 \mathrm{a} 4) \times(5 \mathrm{a} 8)^{1 /}$ & $(1) \times(3 \mathrm{a} 4)$ & $(2) \times(3+4)$ & $(3) \times(4)$ & $(5) \times(6 \mathrm{a} 8)$ & $(6) \times(7+8)$ & $(7) \times(8)$ \\
\hline \multirow{2}{*}{ Crescimento (\%) } & $98,00^{*}$ & 100 & $103,50^{*}$ & 96,09 & 100,00 & 101,09 & 102,32 \\
\cline { 2 - 9 } & 101,46 & 97,33 & 94,25 & 92,40 & 101,95 & 102,28 & 102,45 \\
\hline \multirow{2}{*}{ P liberado ( $\left.\mathrm{g} \mathrm{L}^{-1}\right)$} & $29.459,62^{*}$ & $29.523,33$ & $30.231,85^{*}$ & $28.947,40$ & $19.189,99$ & $18.851,85$ & $18.887,40$ \\
\cline { 2 - 9 } & $18.981,29$ & $29.438,39$ & $29.041,66$ & $29.135,92$ & $18.911,72$ & $18.941,66$ & $18.995,92$ \\
\hline
\end{tabular}

* Contrastes significativos a 5\% de probabilidade. ${ }^{1 /}$ Tratamentos: 1 e 5 - sem aplicação de herbicidas; 2 e 6 - trifloxysulfuron-sodium; 3 e 7 - ametryn; 4 e 8 - trifloxysulfuron-sodium + ametryn, avaliados respectivamente sobre os isolados bacterianos Sac 4 e Sac 13 .
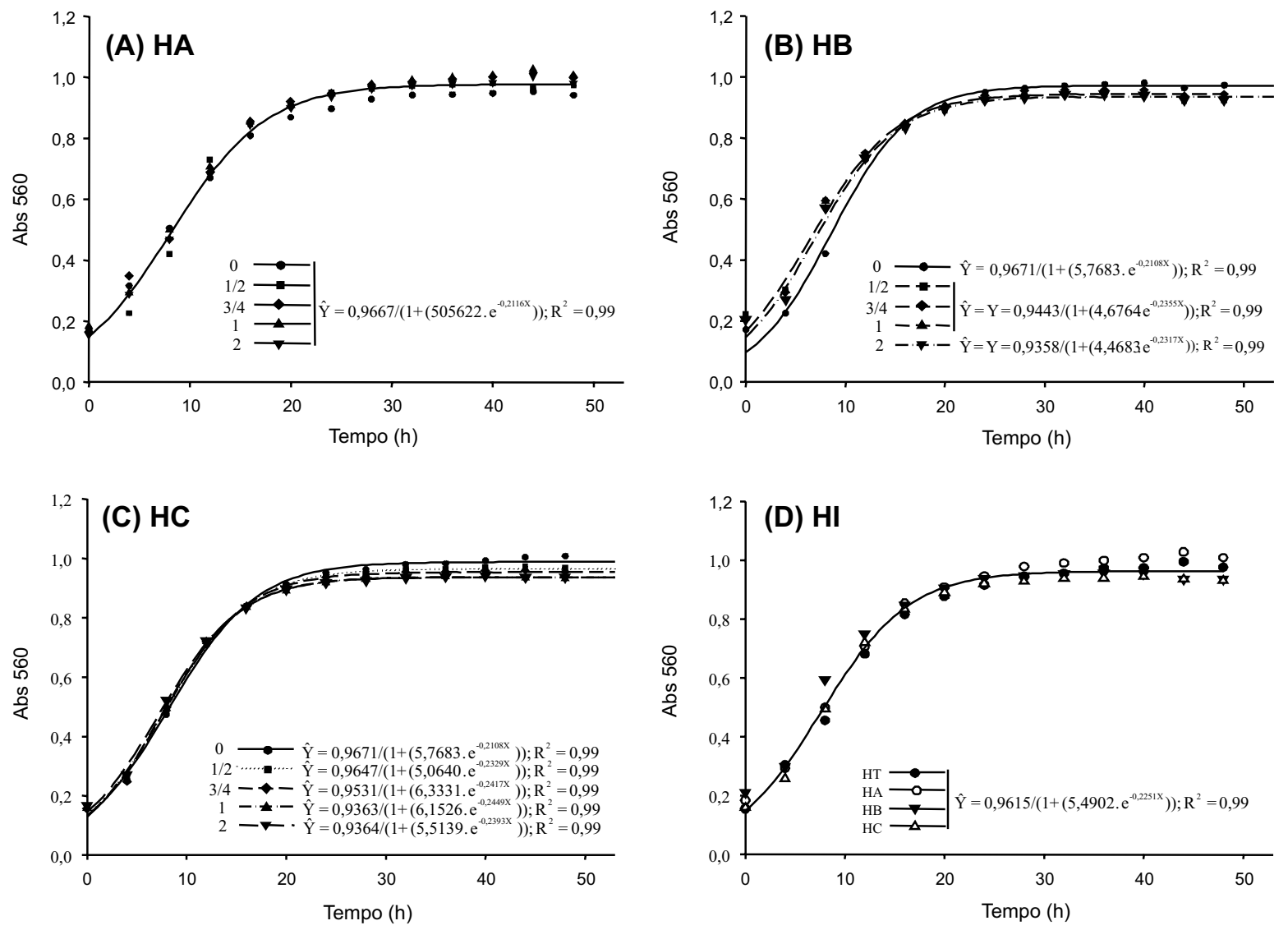

Figura 1 - Curvas de crescimento do isolado bacteriano ( $\mathrm{Sac} 4$ ) da rizosfera de cana-de-açúcar, cultivado em meio caldo nutriente por $48 \mathrm{~h}$ a $30^{\circ} \mathrm{C}$, na presença dos herbicidas trifloxysulfuron-sodium (HA), ametryn (HB) e trifloxysulfuron-sodium + ametryn (HC), nas doses de $0,1 / 2,3 / 4,1$ e 2 vezes a dose de referência, e de todas as formulações na dose de referência (HI). Viçosa-MG, 2008.

Verificou-se que o crescimento do isolado Sac 13 na presença dos herbicidas foi afetado em todas as doses testadas (Figura 2A, B, C), com exceção de $3 / 4$ e 1 vez a dose de referência de trifloxysulfuron-sodium, sendo representadas por único modelo (Figura 2A). O ametryn apresentou maior efeito no crescimento desse isolado, uma vez que o modelo não foi significativo para as doses de $3 / 4,1$ e 2 vezes a dose de referência (Figura 2B). Na dose de referência, os herbicidas alteram a taxa de crescimento bacteriano em relação à testemunha, 

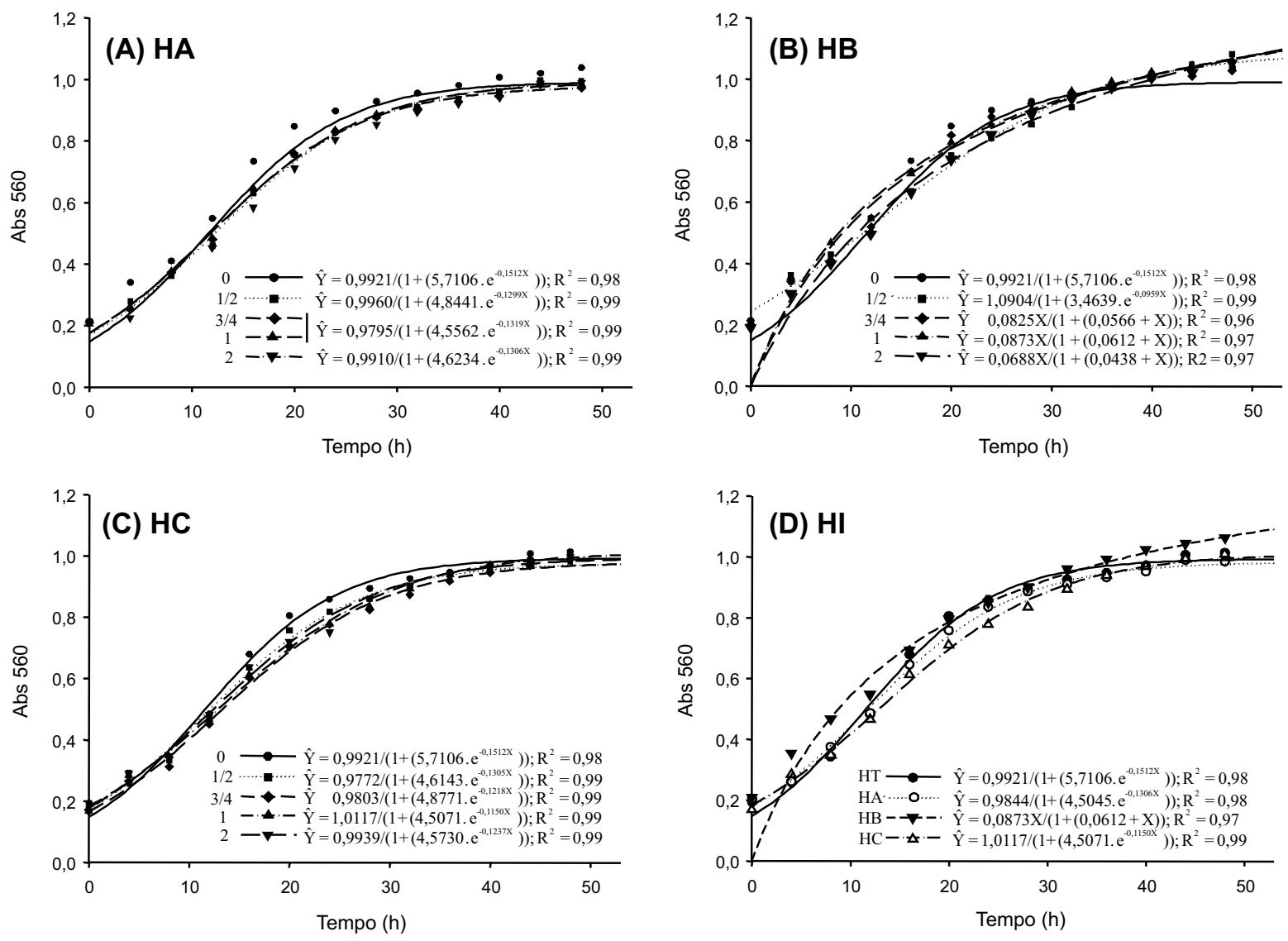

Figura 2 - Curvas de crescimento do isolado bacteriano (Sac 13) da rizosfera de cana-de-açúcar, cultivado em meio caldo nutriente por $48 \mathrm{~h}$ a $30^{\circ} \mathrm{C}$, na presença dos herbicidas trifloxysulfuron-sodium (HA), ametryn (HB) e trifloxysulfuronsodium + ametryn (HC), nas doses de $0,1 / 2,3 / 4,1$ e 2 vezes a dose de referência, e de todas as formulações na dose de referência (HI). Viçosa-MG, 2008.

indicando que esse isolado é mais sensivel aos herbicidas, comparado ao Sac 4 (Figura 2 D).

Conclui-se que, independentemente do herbicida avaliado, o crescimento relativo e a taxa de crescimento in vitro das bactérias provenientes da rizosfera de cana-de-açúcar são afetados de forma diferenciada. No entanto, a atividade solubilizadora de fosfato inorgânico foi pouco influenciada pela presença dos herbicidas. Entre os herbicidas testados e as características avaliadas, o trifloxysulfuronsodium demonstrou ser pouco tóxico às bactérias solubilizadoras de fosfato inorgânico.

\section{AGRADECIMENTOS}

Ao Conselho Nacional de Desenvolvimento Científico e Tecnológico (CNPq), pela concessão de bolsas e pelo apoio financeiro para a realização da pesquisa.

\section{LITERATURA CITADA}

ALVES, S. B.; MOINO Jr., A.; ALMEIDA, J. E. M. Produtos fitossanitários e entomopatógenos. In: ALVES, S. B (Eds.). Controle microbiano de insetos. São Paulo: FEALQ, 1998. p. 217-238

BARROSO, C. B.; NAHAS, E. The status of soil phosphate fractions and the ability of fungi to dissolve hardly soluble phosphates. Appl. Soil. Ecol., v. 29, n. 1, p. 73-83, 2005.

BRAGA, J. M.; DEFELIPO, B. V. Determinação espectrofotométrica de fósforo em extratos de solos de plantas. R. Ceres, v. 21, n. 113, p. 73-85, 1974

DAS, A. C.; DEBNATH, A.; MUKHERJEE, D. Effect of the herbicides oxadiazon and oxyfluorfen on phosphates solubilizing microorganisms and their persistence in rice fields. Chemosphere, v. 53, n. 3, p. 217-221, 2003.

DAS, A. C.; MURKHERJEE, D. Insecticidal effects on soil microorganisms and their biochemical processes related to soil fertility. World J. Microbiol. Biotechnol., v. 14, n. 6, p. 903-909, 1998. 
DEBNATH, A.; DAS, A. C.; MUKHERJEE, D. Persistence and effect of butachlor and basalin on the activities of phosphate solubilizing microorganisms in wetland rice soil.

B. Environ. Contam. Toxicol., v. 68, n. 5, p. 766-770, 2002.

FREITAS, J. R.; BANERJEE, M. R.; GERMIDA, J. J. Phosphate solubilizing rhizobacteria enhance the growth and yield but not uptake of canola (Brassica napus L.). Biol. Fert. Soils, v. 24, n. 4, p. 358-364, 1997.

GRAYSTON, S. J.; VAUGHAN, D.; JONES, D.

Rhizosphere carbon flow in trees, in comparison with annual plants: the importance of root exudation and its impact on microbial activity and nutrient availability. Appl. Soil. Ecol., v. 5, n. 1, p. 29-56, 1996.

GYANESHWAR, P. et al. Role of soil microrganisms in improving P nutrition of plants. Plant Soil, v. 245, n. 1 p. $83-93,2002$

KUMAR, V.; NARULA, N. Solubilization of inorganic phosphates and growth emergence of wheat as affected by Azotobacter chroococcum mutants. Biol. Fert. Soils, v. 28, n. 3, p. 301-305, 1999.

LAW, S. E. Agricultural electrostatic spray application: a review of significant research and development during de $20^{\text {th }}$ century. J. Electrostat., v. 51, n. 1, p. 25-42, 2001.

MADHAIYAN, $M$. et al. Influence of pesticides on the growth rate and plant-growth promoting traits of Gluconacetobacter diazotrophicus. Pestic. Biochem. Phys., v. 84 , n. 2, p. 143-154, 2006

MALKONES, H. P. Comparison of the effects of differently formulated herbicides on soil microbial activities a review. $\mathbf{J}$.

Plant Dis. Protect., v. 8, n. 5, p. 781-789, 2000.

MASSENSSINI, A. M. et al. Atividade de isolados bacterianos solubilizadores de fosfato na presença de formulações comerciais de glyphosate. Planta Daninha, v. 26, n. 4, p. $815-823,2008$

MOREIRA, F. M. S.; SIQUEIRA, J. O. Microbiologia e bioquímica do solo. 2.ed. Lavras: Universidade Federal Lavras, 2006. 729 p.

NAHAS, E. Factors determining rock phosphate solubilization by microorganisms isolated from soil. World $\mathbf{J}$. Microbiol. Biotecnol., v. 12, n. 6, p. 567-572, 1996

NAUTIYAL, C. S. et al. Stress induced phosphate solubilization in bacteria isolated from alkaline soils. FEMS Microbiol. Lett., v. 182, n. 2, p. 291-296, 2000

NEGRISOLI, E. et al. Seletividade de herbicidas aplicados em pré-emergência na cultura da cana-de-açúcar tratada com nematicidas. Planta Daninha, v. 22, n. 4, p. 567-575, 2004
NÓBREGA, R. S. A. et al. Tolerância de bactérias diazotróficas simbióticas à salinidade in vitro. Ci. Agrotec., v. 28, n. 4 , p. $899-905,2004$

NOVAIS, R. F.; SMYTH, T. J.; NUNES, F. N. Fósforo. In: NOVAIS, R. F. et al. (Eds.) Fertilidade do solo. Viçosa, MG: Universidade Federal de Viçosa, 2007. p. 472-550.

REGAZZI, A. J.; SILVA, C. H. O. Teste para verificar a igualdade de parâmetros e a identidade de modelos de regressão não-linear. I dados no delineamento inteiramente casualizado. R. Mat. Estat., v. 22, n. 3, p. 33-45, 2004

REIS, M. R. et al. Ação de herbicidas sobre microrganismos solubilizadores de fosfato inorgânico em solo rizosférico de cana-de-açúcar. Planta Daninha, v. 26, n. 2, p. 333-341, 2008a.

REIS, M. R. et al. Atividade microbiana em solo cultivado com cana-de-açúcar após aplicação de herbicidas. Planta Daninha, v. 26, n. 2, p. 323-331, 2008b.

REIS, M. R. et al. Dinâmica de nutrientes em tecidos foliares de cana-de-açúcar após aplicação de herbicidas. Planta Daninha, v. 26, n. 1, p. 175-184, 2008c.

RODRÍGUEZ, H.; FRAGA, R. Phosphate solubilizing bacteria and their role in plant growth promotion.

Biotechnol. Adv., v. 17, n. 4, p. 319-339, 1999.

SANTOS, J. B. et al. Efeitos de diferentes formulações comerciais de glyphosate sobre estirpes de Bradyrhizobium. Planta Daninha, v. 22, n. 2, p. 293-299, 2004.

SIQUEIRA, J. O.; ANDRADE, A. T.; FAQUIN, V. O papel dos microrganismos na disponibilização e aquisição de fósforo pelas plantas. In: YAMADA, T.; ABDALLA, S. R. S. (Eds.) Fósforo na agricultura brasileira. Piracicaba: ESALQ/USP, 2004. p. $117-156$.

SILVA, A. A. et al. Herbicidas: classificação e mecanismo de ação. In: SILVA, A. A.; SILVA, J. F. (Eds). Tópicos em manejo de plantas daninhas. Viçosa, $\mathrm{MG}$ : Universidade Federal de Viçosa, 2007. p. 83-148.

SILVA FILHO, G. N.; VIDOR, C. Solubilização de fosfatos por microrganismos na presença de fontes de carbono. $\mathbf{R}$.

Bras. Ci. Solo, v. 24, n. 2, p. 311-319, 2000.

SUNDARA, B.; NATARAJAN, V.; HARI, K. Influence de phosphorus solubilizing bacteria on the changes in soil available phosphorus and sugarcane and sugar yields. Field Crop Res., v. 70, n. 1, p. 43-49, 2002.

VIVIAN, R. et al. Persistência e lixiviação de ametryn e trifloxysulfuron-sodium em solo cultivado com cana-deaçúcar. Planta Daninha, v. 25, n. 1, p. 111-124, 2007. 